EPiC Series in Computing
Volume 52, 2018, Pages 168-186
$\begin{aligned} & \text { ICT4S2018. 5th International Conference on Informa- } \\ & \text { tion and Communication Technology for Sustainability }\end{aligned}$

\title{
A high-level estimate of the material footprints of the ICT and the E\&M sector
}

\author{
Jens Malmodin ${ }^{1}$, Pernilla Bergmark ${ }^{1}$ and Sepideh Matinfar ${ }^{1}$ \\ ${ }^{1}$ Ericsson Research, Ericsson AB, Stockholm, Sweden \\ jens.malmodin@ericsson.com, pernilla.bergmark@ericsson.com and sepideh.matinfar@ericsson.com
}

\begin{abstract}
This paper attempts to make a high-level estimate of the material footprints of the Information and Communication Technology (ICT) and Entertainment and Media (E\&M) sectors for one year from four different perspectives while including the full life cycle of products and applying a top-down perspective. The four perspectives explored are: i) amount of materials used; ii) carbon footprint of the materials focusing on Raw Materials Acquisition (RMA) and End of Life Treatment (EoLT) stages; iii) material resource depletion; and iv) toxicity of materials.

For the given assumptions, it is estimated that the sectors represent about $0,5 \%$ of the global annual usage of the selected materials, and for several materials (indium, gallium and germanium), ICT and E\&M usage represents as much as $80-90 \%$ of the overall usage. Their use of materials represents about $0.9 \%$ of the carbon footprint for the selected materials, and about $0.1 \%$ of the total global carbon footprint, while the sectors material resource depletion potential is estimated to be between $13 \%$ and $48 \%$ of overall global depletion for the selected materials, depending on impact assessment method. Finally, the for toxicity of the selected materials, plus cement production, ICT and E\&M are estimated to represent about $3.3 \%$, based on ReCiPe. Toxicity and resource depletion results and the mass result for specific materials all indicate that the ICT and E\&M sectors play a larger role than their average share of the total annual materials usage indicates, and gold and copper are identified as the most impacting materials. The applied top-down method provide only coarse estimates and further research is needed based on bottom-up methods.
\end{abstract}

Keywords-ICT, ICT sector, E\&M, E\&M sector, EEE, material footprint, material carbon footprint, resource depletion potential, mass, toxicity 


\section{Introduction and background}

The term carbon footprint refers to a well-established concept which is commonly understood as the life cycle carbon equivalent emissions related to a product [1] or other types of entities. In this paper different ways to estimate a corresponding material footprint for the ICT and E\&M sectors, are explored and discussed, using top-down approaches. The term material footprint was perhaps first suggested in [2] where material footprints by mass and economic value were estimated and discussed on a per country level. A consumption perspective was used in line with studies that calculated the carbon footprint per country with a consumption perspective [3]. In the same area, [4] examined how circular the global material economy was in 2005. The paper argued that the global material economy is far from being circular with a total recycling rate below 50\%. About $62 \mathrm{Gt}$ materials and fuels were used in 2005, which can be compared to the $70 \mathrm{Gt}$ estimated for 2008 in [2] - and the $80 \mathrm{Gt}$ estimated by this study for 2015 (see Section II.A for details).

A materials footprint is closely related to the concept of circular economy [5]. The circular economy concept points to the importance of using and re-using all the materials of a value chain in an optimized way which in turn makes a quest for better and more sustainable economization of materials and point to, among others, the increased need for reuse and recycling. Currently, a fast increase in material and metal demand is experienced that accelerated around 1995. This holds true for most materials except for paper and wood [6]. Figure 1 gives a simplified illustration of this acceleration where usage of each material has been indexed in comparison to 1995 levels (i.e. the level of 1995 is defined as 100\%). The increase in material demand from around 1995 is to a large extent related to the accelerated economic development that took place in China in the 90's and in other developing countries since 1995.

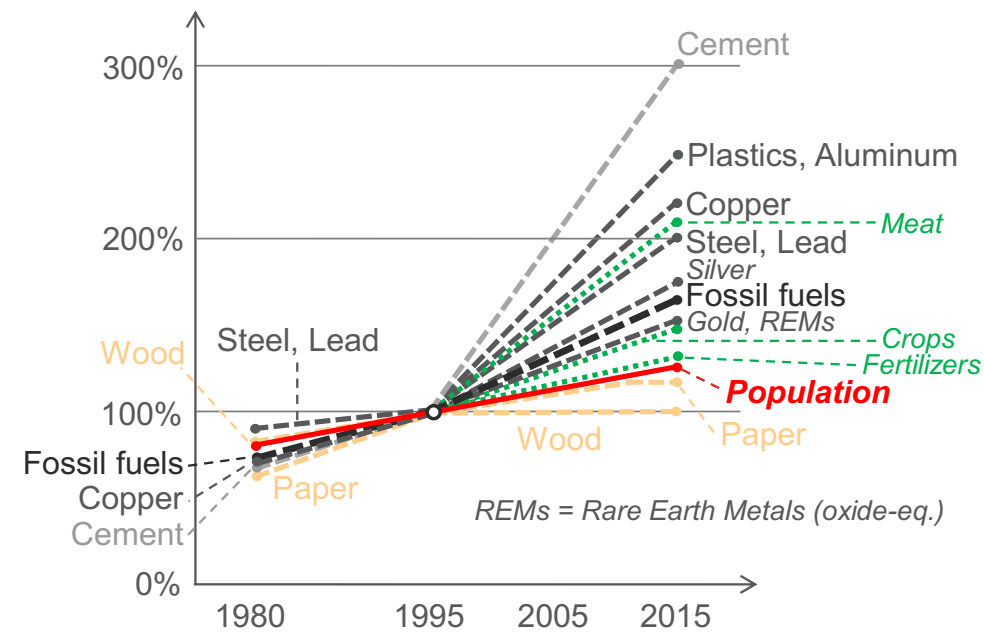

Figure 1: The material demand around 1980, 1995 and 2015 (Indexed, 1995 demand $=100 \%$ ). The figure is summarizing information from [4] and the different sources listed in Table IV. The dashed lines are linear interpolations intended to illustrate the trend and do not represent the detailed development between these years.

Recycling assumptions are crucial for the results when material footprints are estimated, as will be shown in section III. Figure 2 illustrates the importance of recycling to keep a material resource available for society over time. Without high recycling rates a material resource will be consumed relatively fast (i.e. within decades/centuries) and can thus provide less value to society overall, even if product life times are extended by reuse, and product use is made more efficient by sharing. 


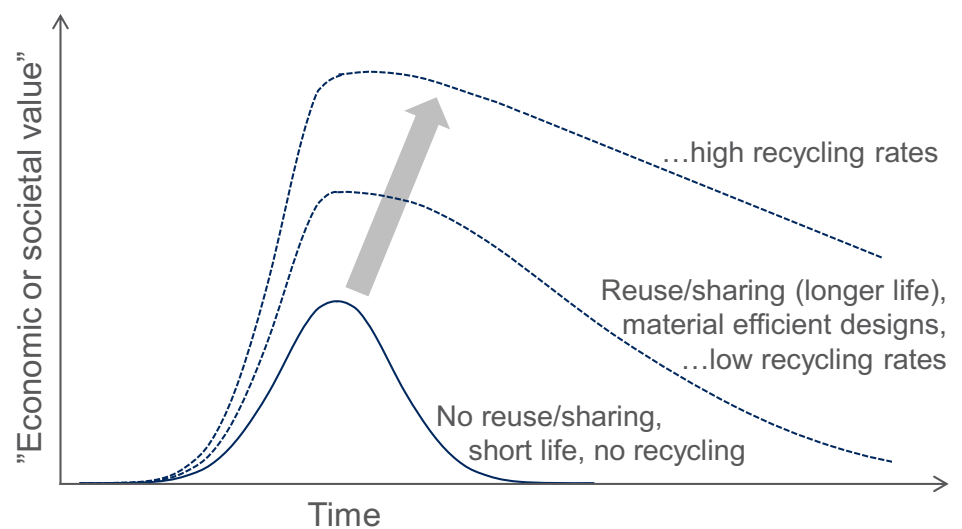

Figure 2: A principal figure describing the value to the economy or society from using a material resource in products/services and how the use and value are reduced over time unless the material resource is conserved through reuse, sharing and recycling.

Figure 3 illustrates, for the period 1985-2015, per material, the estimated global recycling rates, and the global share of recycled materials as percentage of total annual materials usage, in accordance with $[4,6-13]$.

On a positive note, a larger share of the metal content in scrap is recycled. Referring to Figure 3 which illustrates the present situation, steel, iron, and lead have shown increase recycling rates during the period, while, copper recycling rates have fluctuated, and the share for steel [9] and lead [10] is now approaching $70 \%$. For the future, it is estimated that an even larger share of metals in products produced today will be recycled in the future, e.g. about $85 \%$ for steel [9]. However, recycling rates of $100 \%$ could not be reached due to somewhat complex materials mixes and losses due to forces of nature such as corrosion, tearing and wearing. [14] describes this as "increased recycling is not a panacea: The current rapid growth of the materials stock in the technosphere necessitates continuous natural resource depletion and recycling itself is ultimately limited by thermodynamics".

In spite of the often increasing recycling rates, the share of recycled metals in production, as compared to the overall input of these metals including also virgin metals from ore, is in most cases either decreasing or fluctuating (in the figure this holds for all materials but lead) which, according to the importance of recycling as outlined in Figure 2, shows the need for better economization of materials.

Overall, the material intensity of the global economy [15] is increasing, and the main reason for the decrease in the recycled content share in metal production, is the fast increase in material and metal demand shown in Figure 1 - the metals recycled today emerge from much lower production volumes, so that even a full recycling of these metals would not meet today's demands [7]. 


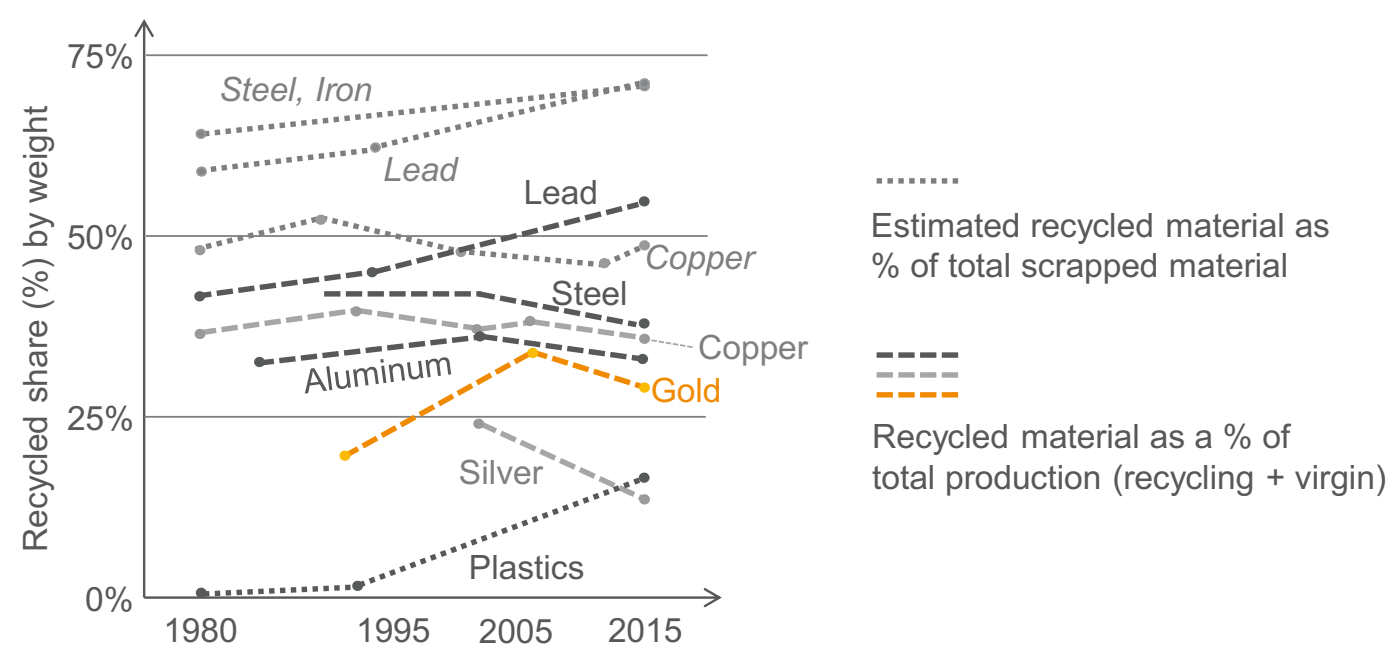

Figure 3: Global recycling rates and share of recycled materials in total materials production for some metals and for plastics. The lines are linear interpolations to show the trend and do not represent the detailed development between the stated years (Sources: [4, 6-13]).

It is clear from the above trends that the use of materials needs careful monitoring for all sectors to secure the long-term supply of materials. Taken together with the life cycle contribution from materials to climate change and to the exposure of eco-systems and human beings to toxic substances, there are several well-founded reasons for all sectors to monitor their materials usage and their environmental impacts related to materials. For the same reasons, this paper tries to estimate the materials footprint for the ICT and E\&M sectors.

\section{Scope and boundaries}

This study focuses on the annual usage of a selection of materials significant to ICT and E\&M, mainly metals but also platics, cardboard, glass ceramics etc., while excluding fuels, chemicals, gravel, sand and other bulk substances. A complete list of the selected materials is found in Table IV and the rational for including only these materials is given in Section II.A. The study is limited to the annual use of materials, thus it does not consider the materials of the already installed equipment.

The boundaries of ICT and E\&M sectors are defined according to Table III which list the product categories that are considered in this study. These boundaries are aligned with [16]. As an intermediate step needed to derive the ICT and E\&M footprints from overall global materials usage, data was collected also for the wider Electrical and Electronic Equipment (EEE) sector which these sectors form part of. The applied boundaries for EEE, in terms of included product categories, are defined by Table I.

The study is covering four different material footprints:

i. Material footprint by mass and share of mass: This is the most basic material footprint and can be defined as mass or share of mass that is added within the sector boundaries during one year. As stated, this study is limited to the selected materials that are significant to ICT and E\&M as specified by Table V.

ii. Material carbon footprint: This footprint is defined as the carbon footprint of the RMA stage of the life cycle of all ICT and E\&M products produced in one year - a carbon footprint of the materials. 
iii. Material toxicity footprint: This represents the material footprint with regards to the human and ecosystem toxicity potential for the RMA and EoLT for all products of the studied sectors produced in one year. The materials' toxicity potential footprint is based on the ReCiPe method and covers the selected materials according to Table V plus cement. Cement is mainly included to align with the reference source. Social impacts and working conditions are beyond the scope of this study.

iv. Material resource depletion footprint: Many raw material resources, especially metals, have become scarcer and their prices have increased fast during the last decades [REF]. Some of these metals are crucial ICT and E\&M products, and more generally for EEE. For this reason, another potential environmental impact category of concern is the material resource depletion or the abiotic depletion potential (ADP).

\section{Methodology and data collection}

\section{A. Data collection approaches}

To model the materials usage this study is mainly applying a top-down approach but uses bottom-up data to enable the allocation of materials to the studied sectors when high-level data is not available or is not considered to have sufficient quality, as further specified in this section. The data collection procedure includes collection of the following data

i. Overall global materials usage with regards to total weights (Section II.B)

ii.. Allocation of materials to the ICT and E\&M sector level. In this part three alternative approaches are applied based on data availability:

a. Option I: Data on ICT and E\&M's share of a material exists and is applied directly (Section II.C).

b. Option II: Data is available only for EEE, but the material is used only for specific electronics, so ICT and E\&M's share of this material is allocated in proportion to their use of these electronics (Section II.C).

c. Option III: Data is available only for EEE and is allocated to ICT and E\&M in proportion to their relative overall weight. The weight is derived from device/ equipment level (Section II.C).

iii. Data for recycling (Section II.D).

\section{B. $\quad$ The overall Global materials usage}

This section summarizes the data collected related to the overall global material usage, which is later used as a reference to put the ICT and E\&M materials usage into context. The total annual use of materials ( $45 \mathrm{Gt}$ ) and fuels ( $35 \mathrm{Gt}$ ) in society equals $80 \mathrm{Gt}$, based on [2,4,7] and is shown in Figure 4 below. It was noted during the data collection that the total annual fresh water used globally is in the order of 300 Gton or about four times the total amount of materials and fuels in Figure 4. 


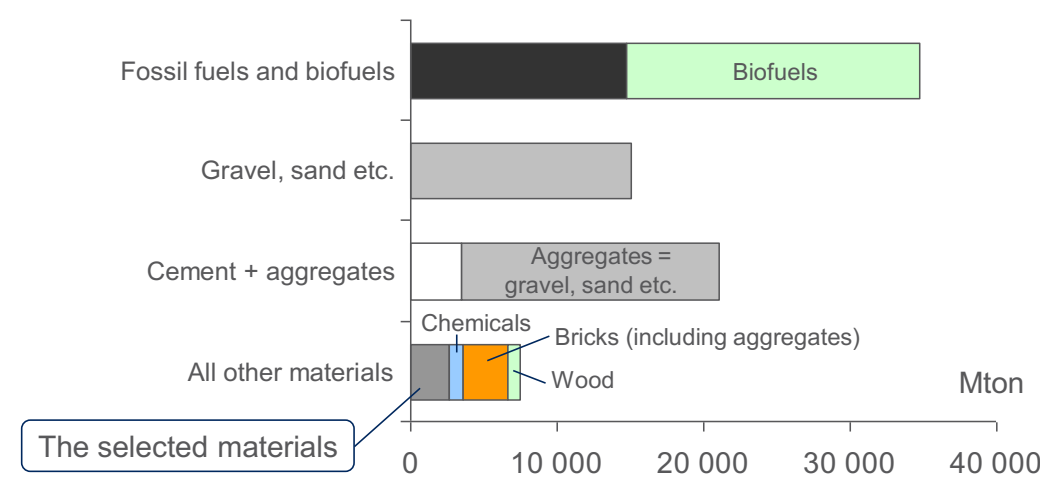

Figure 4: Total global annual use of materials and fuels in society.

The total amount of sand, soil and other masses that are moved/handled annually is estimated to about $3000 \mathrm{Gt}$ - or ten times as large as the fresh water use. Finally, total water use in e.g. hydropower dams is about ten times larger than masses moved/handled and about 100 times larger than fresh water use.

The remaining part of this study will focus on a number of selected materials, further defined in Table IV, for which ICT and E\&M contributes significantly to the annual use, as it makes little sense to compare the material footprints of the ICT and E\&M sectors to all the $80 \mathrm{Gt}$ materials and fuels from Figure 4, as the overall weight is dominated by materials to which ICT and E\&M contributes only to a low extent, if at all, as is further illustrated in Figure 4.

The selected materials are materials for which ICT and E\&M represent a significant share of the overall usage. These materials include, as shown in Section III, Figure 5 and Table IV, iron/steel, plastics, cardboard, ceramics, glass and metals but exclude cement/concrete, bricks, chemicals (which gathers e.g. asphalt, gypsum, fertilizers, and salt), and wood materials which are less related to ICT and E\&M. The overall annual use of the selected materials equal $2.6 \mathrm{Gt}$, i.e. about $6 \%$ of all materials not counting fuels. For each selected material, data was collected from material producers and their organizations, with regards to the totally produced weight per material for one year, from the sources listed in Table IV.

In terms of carbon equivalent emissions, the overall global material carbon footprint is estimated to have grown from about $13 \%$ of the total global carbon footprint (total life cycle perspective including land use) in 2000 to about $17 \%$ in 2010-2015 [17]. The increase between 2000 and 2010 is mainly due to increased steel and cement production, primarily in China but also in other developing countries like India. The metal related share of this carbon footprint (which represent a large part of the selected materials) is estimated to be about $3.7 \mathrm{Gt} \mathrm{CO}_{2} \mathrm{e}$ corresponding to about $8 \%$ of the overall global carbon footprint in 2015. This could be compared to the 3.4 Gt estimated by [19] for 2008.

\section{Modelling of the material usage of ICT and E\&M per device/ equipment type}

In this step, the materials usage of ICT and E\&M was derived. As a start, estimates from the material producers and organizations (see Table IV for references) were collected with regards to the distribution of materials between different sectors. Based on this, it was concluded that the data in many cases provided details only for EEE level, but not for ICT and E\&M specifically. The UN e-waste Monitor estimates "small IT and display" e-waste to $9.3 \mathrm{Mt}$ in 2014 [18] and $10.5 \mathrm{Mt}$ in 2016 [19] which was used as a benchmark to this study (11.7 Mt new products in 2015 estimated, see Table II and III) but there are differences in time and system boundaries. Material content estimates is only done on an EEE level in $[18,19]$ which include lamps and appliances but not much else. To study the ICT and E\&M sectors in greater detail, the approaches according to II.A (Option I-III) were applied.

For Option I, specific data with regards to ICT's share of the materials were available and collected as listed in Table III. For Option II, which was used for materials that are only present in electronics, the 
ICT and E\&M sectors' share of some component categories were derived based on market value, as outlined in Table I. This model is considered to give better estimates for materials in electronics than Option III, as electronics represent only a small fraction of the overall weight which is the basis for Option III. The component categories used for this approach were integrated circuits (IC), printed circuit boards (PCB) and displays, which each has its specific material composition with regards to the selected materials and include many of the rare and valuable metals. For these component categories, ICT and E\&M are also the dominating users within the EEE sector.

\begin{tabular}{|l|c|c|}
\hline & Total market value [B\$) & ICT and E\&M sectors share \\
\hline Integrated circuits (IC) & 330 & $80 \%^{1}$ \\
\hline Printed circuit boards (PCB) & 60 & $80 \%^{1}$ \\
\hline Displays & 100 & $95 \%^{1}$ \\
\hline
\end{tabular}

Table 1: ICT and E\&M sectors component use

${ }^{1}$ Share estimated based on data from IC Insights [20] and IPC [21].

For Option III, as a first step, EEE's shares of the selected materials were collected from the material producers and organizations as specified in Table IV which details these data and their data sources. With materials usage known down to an EEE level, the next step focused on deriving the ICT and E\&M weight as a portion of the EEE weight. To estimate the overall EEE weight, EEE product categories were identified according to Table I, and sales statistics were collected for these with regards to weight and annual production. In addition, the total ICT \& E\&M weight was derived, through multiplying the collected volumes and weight of each product category, before adding them together in accordance with Table III . Finally, the ICT and E\&M weight was calculated to be in the order of $10 \%$ of the overall EEE weight. When applying Option III this value is used as a proxy for ICT and E\&M's share of a material allocated to EEE, under the best-effort assumption that material proportions within ICT and E\&M equals those of EEE. This assumption is further addressed in the discussion, section IV.

The process of deriving the ICT and E\&M weight according to Option III, should be described in greater detail. Firstly, shipment data were collected for 2015, and typical weights of individual devices were estimated based on the experience of the authors. From these, the total weight per product category were calculated as specified in Table III. In this step, it turned out to be easier to find data for user devices than for network equipment. For network equipment, inhouse Ericsson data and data given to the company under NDA, were therefore used to estimate the weight of the overall networks category presented in Table III. This use of confidential data is addressed in the discussion, section IV. In a final step, the individual weights of all categories were summed up into a resulting ICT and E\&M weight.

\begin{tabular}{|l|c|c|l|}
\hline EEE subsector & $\begin{array}{c}\text { Market } \\
\text { value [B\$] }\end{array}$ & $\begin{array}{c}\text { Product / packaging } \\
\text { weight [kt] }\end{array}$ & Source \\
\hline ICT and $\boldsymbol{E} \boldsymbol{\&} \boldsymbol{M}$ & $\mathbf{1 1 0 0}$ & $\mathbf{1 1 7 0 0 / 2 5 0 0}$ & From Table III \\
\hline Cables & $105^{1}$ & $12500^{1}$ & {$[22]$} \\
\hline Appliances (including residential HVAC) & 480 & $\sim 33000 / \sim 5000$ & IHS [23] \\
\hline Batteries & 50 & 7000 & Estimate based on lead use [10] \\
\hline Automotive & 160 & 5000 & Estimate \\
\hline Lighting (lamps only) & 100 & $\sim 1000 / \sim 200$ & Phillips \\
\hline Electric motors (small and medium) & 90 & $\sim 1000$ & ABB [24] \\
\hline Medical equipment & 45 & $?$ & \\
\hline PV panels & 100 & 4000 & Estimate based on [25] \\
\hline Electric tools (small electric motors) & $20-30$ & $\sim 1000 / \sim 200$ & FMI [26] \\
\hline Others ${ }^{2}$ & $?$ & $\sim 23000$ & Residual part \\
\hline EEE totals $^{\mathbf{3}}$ & $\sim \mathbf{2 3 0 0}$ & $\mathbf{2 8 / 8 + M t}$ & \\
\hline
\end{tabular}


Table 2: EEE product categories data

${ }^{1}$ Excluding cables included in other end-use categories.

${ }^{2}$ This sub-category include other HVAC, security, aviation, military/space, sensors/tags (building automation), building grids, and others

${ }^{3}$ This study does not consider large electric furnaces, industrial electrolysis, large HVAC/cooling, large grid power cables, grid components, and large electric motors as EEE.

For some categories like cables, batteries, optical discs and retail packaging, no individual weights were collected, but an estimated overall weight of the category was supposed to provide sufficient accuracy. These categories are thus listed in Table III without individual weights, and, when the ICT and E\&M category forms part of a corresponding EEE category - like for cables where the signal and fiber cable segments are allocated to ICT and E\&M while being part of overall cable input data - estimates have been validated towards the input data for Table II and measures have been taken to avoid double counting between Table II and III to the extent possible.

\begin{tabular}{|c|c|c|c|c|}
\hline Shipments & $\begin{array}{l}\text { Shipments } \\
\text { 2015 } \\
\text { [million] }\end{array}$ & $\begin{array}{l}\text { Est. weight } \\
\text { per average } \\
\text { unit }[\mathrm{kg}]\end{array}$ & $\begin{array}{l}\text { Est. total } \\
\text { shipped } \\
\text { weight }[\mathrm{kt}]\end{array}$ & $\begin{array}{l}\text { Notes and data sources (shipments } \\
\text { 2015) } \\
\text { Weights per average unit is based on } \\
\text { former Ericsson publications }[20]\end{array}$ \\
\hline $\begin{array}{l}\text { Fixed phones } \\
\text { (PSTN+VoIP) }\end{array}$ & 200 & 0.2 & 40 & $\begin{array}{l}\text { Estimated based on telephony } \\
\text { subscriptions (ITU) }\end{array}$ \\
\hline Smartphones & 1433 & 0.15 & 215 & \multirow[b]{2}{*}{$\begin{array}{l}\text { Gartner, Worldwide Quarterly Device } \\
\text { Shipments, } \\
\text { https://www.gartner.com/newsroom/id/3 } \\
\text { 187134 } \\
\text { IDC, Worldwide Quarterly Mobile } \\
\text { Phone Tracker } \\
\text { https://www.idc.com/tracker/showprodu } \\
\text { ctinfo.jsp?prod id=37 }\end{array}$} \\
\hline $\begin{array}{l}\text { Other mobile } \\
\text { phones }\end{array}$ & 537 & 0.1 & 54 & \\
\hline $\begin{array}{l}\text { CPE (e.g. } \\
\text { modems and } \\
\text { gateways) }\end{array}$ & 184 & 0.5 & 77 & Future Source (see reference below) \\
\hline Tablets & 208 & 0.75 & 156 & \multirow{3}{*}{$\begin{array}{l}\text { IDC, Worldwide Quarterly Personal } \\
\text { Computing Device Tracker, } \\
\text { https://www.idc.com/tracker/showprodu } \\
\text { ctinfo.jsp?prod_id=1541 } \\
\text { Gartner, Worldwide Quarterly Device } \\
\text { Shipments, } \\
\text { https://www.gartner.com/newsroom/id/3 } \\
\underline{187134}\end{array}$} \\
\hline Laptops & 163 & 1.75 & 285 & \\
\hline Desktops & 114 & 7.5 & 855 & \\
\hline $\begin{array}{l}\text { Computer } \\
\text { displays }\end{array}$ & 130 & 5 & 650 & $\begin{array}{l}\text { IHS, } \\
\text { https://technology.ihs.com/572224/deskt } \\
\frac{\text { op-monitor-market-tracker-q1-2016 }}{\text { (Desktop Monitor Market Tracker) }}\end{array}$ \\
\hline $\begin{array}{l}\text { Computer } \\
\text { peripherals (no } \\
\text { HDDs) }\end{array}$ & (114) & (1) & 114 & $\begin{array}{l}\text { Estimated based on PC shipments and } \\
\text { common peripherals e.g. mouse and } \\
\text { keyboard }\end{array}$ \\
\hline Projectors & 8 & 7.5 & 60 & Future Source (see reference below) \\
\hline Public displays & 3.5 & 50 & 175 & $\begin{array}{l}\text { IHS, } \\
\text { https://technology.ihs.com/572984/publi } \\
\text { c-display-market-tracker-q1-2016 } \\
\text { (Public Display Market Tracker) }\end{array}$ \\
\hline $\begin{array}{l}\text { Surveillance } \\
\text { cameras }\end{array}$ & 28 & 5 & 80 & $\begin{array}{l}\text { IHS, } \\
\text { https://technology.ihs.com/Research-by- } \\
\text { Market/551540/security-technology () }\end{array}$ \\
\hline
\end{tabular}




\begin{tabular}{|c|c|c|c|c|}
\hline $\begin{array}{l}\text { Payment } \\
\text { terminals }\end{array}$ & 35 & 1 & 35 & $\begin{array}{l}\text { BI Intelligence, } \\
\text { https://www.businessinsider.com.au/the- } \\
\text { global-payment-terminal-market-2014-5 }\end{array}$ \\
\hline Wearables & 46 & 0.15 & 7 & $\begin{array}{l}\text { IDC, Worldwide Quarterly Wearable } \\
\text { Device Tracker, } \\
\text { https://www.idc.com/tracker/showprodu } \\
\text { ctinfo.jsp?prod id }=962 \\
\end{array}$ \\
\hline $\begin{array}{l}\text { Smart meters } \\
\text { (only control } \\
\text { units) }\end{array}$ & 40 & 0.15 & 6 & Pike Research \\
\hline $\begin{array}{r}\text { ICT sector user } \\
\text { devices total: }\end{array}$ & 3213.5 & $(\sim 0.9 \mathrm{~kg})$ & 2749 & \\
\hline TVs & 235 & 15 & 3525 & $\begin{array}{l}\text { Digital TV Research, Digital TV World } \\
\text { Data Book 2016 (May 2016) } \\
\text { https://www.digitaltvresearch.com/prod } \\
\text { ucts/product?id=142 }\end{array}$ \\
\hline $\begin{array}{l}\text { STBs (Set-top } \\
\text { boxes) }\end{array}$ & 265 & 0.5 & 133 & \multirow{7}{*}{$\begin{array}{l}\text { Future Source, } \\
\text { https://www.futuresource- } \\
\text { consulting.com/ } \\
\text { One of the leading analyst for audio and } \\
\text { camera products but also for CPEs } \\
\text { (gateways, modems etc.), STBs and } \\
\text { projectors, and also for optical and } \\
\text { electronic media (discs, memory } \\
\text { sticks/cards, printer consumables) } \\
\text { See also: } \\
\text { CES 2016, Global Tech Spending } \\
\text { Update, Presentation at CES 2016 } \\
\text { January 6-9 Las Vegas (media copy) }\end{array}$} \\
\hline DVD/BD players & 57 & 2 & 114 & \\
\hline Media players & 50 & 1 & 50 & \\
\hline $\begin{array}{l}\text { Home audio } \\
\text { systems }\end{array}$ & 79 & 5 & 395 & \\
\hline $\begin{array}{l}\text { Portable media } \\
\text { players }\end{array}$ & 35 & 0.15 & 5 & \\
\hline Headphones & 320 & 0.5 & 160 & \\
\hline $\begin{array}{l}\text { Cameras, } \\
\text { camcorders }\end{array}$ & 58 & 0.25 & 15 & \\
\hline Game consoles & 37 & 1.75 & 65 & \multirow{3}{*}{$\begin{array}{l}\text { Jon Peddie Research, } \\
\text { https://www.jonpeddie.com/press- } \\
\text { releases/millions-of-android-gaming- } \\
\text { consoles-on-the-horizon/ } \\
\text { http://www.jonpeddie.com/publications/ } \\
\text { console-gaming-hardware-market-study/ }\end{array}$} \\
\hline $\begin{array}{l}\text { Portable game } \\
\text { consoles }\end{array}$ & 18 & 0.5 & 9 & \\
\hline $\begin{array}{l}\text { Arcade game } \\
\text { machines }\end{array}$ & 2.4 & 200 & 480 & \\
\hline $\begin{array}{l}\text { Automotive (all } \\
\text { display products) }\end{array}$ & 75 & 0.75 & 56 & $\begin{array}{l}\text { IHS, } \\
\text { https://technology.ihs.com/572824/small } \\
\frac{\text {-medium-display-market-tracker-q1- }}{2016 \text { (Small / Medium Display Market }} \\
\text { Tracker) }\end{array}$ \\
\hline $\begin{array}{l}\text { E\&M sector } \\
\text { user devices } \\
\text { total: }\end{array}$ & 1231 & $(\sim 4 \mathrm{~kg})$ & 5006 & \\
\hline $\begin{array}{l}\text { Hardcopy } \\
\text { devices }^{1}\end{array}$ & 103 & 10 & 1030 & $\begin{array}{l}\text { IDC, Worldwide Quarterly Hardcopy } \\
\text { Peripherals Tracker } \\
\text { https://www.idc.com/tracker/showprodu } \\
\text { ctinfo.jsp?prod_id=3 }\end{array}$ \\
\hline Servers & 11.1 & 5 & 55 & $\begin{array}{l}\text { IDC, Worldwide Quarterly Server } \\
\text { Tracker } \\
\text { https://www.idc.com/tracker/showprodu } \\
\text { ctinfo.jsp?prod_id=7 }\end{array}$ \\
\hline $\begin{array}{l}\text { HDDs } \\
\text { (additional) }^{2}\end{array}$ & 100 & 0.25 & 25 & $\begin{array}{l}\text { About } 470 \text { million in total (IDC), about } \\
370 \text { million estimated to be already } \\
\text { included in ICT sector user devices } \\
\text { above, e.g. PCs }\end{array}$ \\
\hline
\end{tabular}


A high-level estimate of the material footprints of the ICT and the E\&M sector

J. Malmodin et al.

\begin{tabular}{|c|c|c|c|c|}
\hline $\begin{array}{l}\text { Network } \\
\text { equipment }^{3}\end{array}$ & 10 & & 800 & $\begin{array}{l}\text { Ericsson estimate for node level based } \\
\text { on [20] }\end{array}$ \\
\hline $\begin{array}{l}\text { Cables } \\
\text { (additional/exter } \\
\text { nal) }\end{array}$ & na & & 1000 & Estimate $^{4}$ \\
\hline $\begin{array}{l}\text { Batteries } \\
\text { (additional/exter } \\
\text { nal) }\end{array}$ & na & & 500 & Estimate $^{5}$ \\
\hline $\begin{array}{l}\text { Memory } \\
\text { cards/sticks, } \\
\text { optical discs, } \\
\text { inkjet and toner } \\
\text { cartridges }\end{array}$ & 7000 & na & 340 & Future Source (see reference above) \\
\hline $\begin{array}{l}\text { GRAND } \\
\text { TOTAL: }\end{array}$ & & & 11700 & \\
\hline $\begin{array}{l}\text { Retail product } \\
\text { packaging total: }\end{array}$ & na & & 2500 & Estimate in this study based on RISI [6] \\
\hline $\begin{array}{l}\text { E\&M paper } \\
\text { consumption }\end{array}$ & $n a$ & & 126000 & RISI [6], paper used for media \\
\hline \multicolumn{3}{|c|}{$\begin{array}{l}\text { ICT infrastructure materials (steel, concrete, } \\
\text { gravel etc.) }\end{array}$} & $\sim 20000$ & Ericsson estimate based on [20] \\
\hline
\end{tabular}

Table 3: ICT and E\&M product shipments and weight estimates

${ }^{1}$ Includes printers, copiers, faxes and combo-devices, office and home devices

${ }^{2}$ Additional HDDs not already included in PC and server shipments

${ }^{3}$ Includes mobile base station, fixed access and IP data transmission and core network equipment and internal cabling, includes also data center cabinets but servers listed exclusively, ${ }^{4}$ About $500 \mathrm{kt}$ external cables estimated to already be included in ICT and E\&M user devices, the remaining (this estimate) covers network cables (note that new network cables are not needed at the same pace as network equipment)., ${ }^{5}$ Most small batteries estimated to be "consumed" by ICT and E\&M user devices, the remaining (this estimate) covers back-up batteries (mainly lead types) 


\section{The importance of recycling}

When estimating the material footprint in terms of materials usage, the origin of materials (virgin or recycled) is not considered in this study. For the other three footprints, recycling assumptions plays an important role for the results. In this study, world average recycling rates in line with Figure 3 and Table IV, are assumed both for the input material streams, and for recycling at EoLT. The sensitivity of this assumption is tested for each of the applicable footprints, see further section III.B-D. Furthermore, impacts from the recycling processes are allocated between life cycles using the 50/50 method as defined in [16]. Losses of materials during production (yield losses) have not been included, which corresponds to assuming $100 \%$ recycling of materials waste during the RMA and production stages. The rational for this is that recycling rates of production waste is typically very high and the return time to material recyclers/producers is fast. In reality, it is assumed that such losses could add 10\% to the footprints.

\section{Results and analysis}

\section{A. Material footprint by mass}

The resulting ICT and E\&M usage of the selected materials for one year is given in Table IV, together with input data and intermediate data for total global annual materials production, world average recycled share of materials, EEE use of materials. In addition to the selected materials, Table IV includes information (in italics) regarding the main infrastructure construction materials used by the ICT and E\&M sectors, as well as for the paper used by E\&M. While the infrastructure construction materials are of interest as they represent a large share of the total materials usage of the ICT sector by weight, their share of the potential environmental impacts is limited according to earlier Life Cycle Assessment (LCA) studies [27] and these materials were therefore not included in the selected materials or considered in the calculated footprints. Similarly, physical paper media (a k a printing paper or graphical paper) is the most significant material for the E\&M sector in weight, but is excluded from the footprints as it differs so much in origin and impacts from the other materials of the sector, and to not "hide" the other materials.

Calculated from table IV, the total share of the selected materials used in EEE during one year, corresponds to $110 \mathrm{Mt}$ or about $4 \%$ of all selected materials, and in the ICT and E\&M sectors, $14 \mathrm{Mt}$ corresponding to $0.54 \%$. Thus, in overall weight, ICT and E\&M represents a very small fraction, but the share of rare metals is significantly higher, and for several materials (indium, gallium and germanium), ICT and E\&M usage represents $80-90 \%$ of the overall usage. Figure 5 graphically represents how the selected materials are distributed into different material categories, totally, for EEE, and for ICT and E\&M. 


\begin{tabular}{|c|c|c|c|c|c|c|}
\hline $\begin{array}{l}\text { Key data } \\
2015\end{array}$ & $\begin{array}{c}\text { Total } \\
\text { production } \\
\text { kton }\end{array}$ & $\begin{array}{c}\text { Recycl } \\
\text { ed } \\
\text { share } \\
\%\end{array}$ & $\begin{array}{c}\text { EEE } \\
\text { use } \\
\%\end{array}$ & $\begin{array}{c}\text { ICT+E\&M } \\
\text { use (\% of } \\
\text { EEE use) }\end{array}$ & $\begin{array}{c}\text { ICT+E\&M use } \\
\text { kton } \\
\text { (\% of total use) }\end{array}$ & $\begin{array}{l}\text { Option I, II and } \\
\text { III and Sources } \\
\text { If no source is } \\
\text { listed data is based } \\
\text { on [7]. Note that } \\
\text { [7] excludes } \\
\text { recycling why the } \\
\text { additional sources. }\end{array}$ \\
\hline Iron/Steel & 1600000 & $37 \%$ & $3.6 \%$ & $10 \%$ & $5800(0.36 \%)$ & Option III, [9] \\
\hline $\begin{array}{l}\text { - Stainless } \\
\text { steel }\end{array}$ & -32000 & $32 \%$ & na & na & na & $\begin{array}{l}\text { [29], included in } \\
\text { Iron/Steel (not } \\
\text { treated separately) }\end{array}$ \\
\hline Plastics & 400000 & & $5 \%$ & $15 \%$ & $3000(1 \%)$ & $\begin{array}{l}\text { Option I, [8], } \\
\text { including } \\
\text { packaging }\end{array}$ \\
\hline Cardboard & 250000 & & $8 \%$ & $8 \%$ & $1500(0.6 \%)$ & $\begin{array}{l}\text { Option I, [6], } \\
\text { including } \\
\text { packaging }\end{array}$ \\
\hline Glass & 130000 & & & & & Option II. \\
\hline Ceramics & 125000 & & & na & $\sim 700(0.2 \%)$ & $\begin{array}{l}\text { Estimate based on } \\
\text { display and } \\
\text { printed circuit } \\
\text { board data }\end{array}$ \\
\hline Aluminum & 70000 & $32 \%$ & $6 \%$ & $15 \%$ & $630(0.9 \%)$ & Option I, [11] \\
\hline Copper & 25650 & $37 \%$ & $30 \%$ & $26 \%$ & $1540(6 \%)$ & $\begin{array}{l}\text { Option I, [12], } \\
{[13]}\end{array}$ \\
\hline Manganese & 24000 & & $4 \%$ & $10 \%$ & $96(0.4 \%)$ & Option III \\
\hline Zinc & 14500 & $15 \%$ & $7 \%$ & $10 \%$ & $101(0.7 \%)$ & Option III \\
\hline Chromium & 13600 & $32 \%$ & $7 \%$ & $10 \%$ & $95(0.7 \%)$ & Option III \\
\hline Lead $^{2}$ & 10000 & $50 \%$ & $85 \% \%^{2}$ & $30 \%$ & $450(4.5 \%)$ & Option I, [10] \\
\hline Nickel & 2000 & $32 \%$ & $13 \%$ & $10 \%$ & $26(1.3 \%)$ & Option III \\
\hline Lithium & 650 & & $24 \%$ & $80 \%$ & $122(19 \%)$ & Option II \\
\hline Tin & 365 & $8 \%$ & $47 \%$ & $80 \%$ & $172(38 \%)$ & Option II, \\
\hline Molybdenum & 264 & & $4 \%$ & $10 \%$ & $3(1 \%)$ & Option III \\
\hline Antimony & 163 & & $50 \%$ & $50 \%$ & $41(25 \%)$ & Option I, [30] \\
\hline Cobalt & 140 & & $32 \%$ & $80 \%$ & $36(26 \%)$ & Option II \\
\hline REO or REM & 130 & & $25 \%$ & $80 \%$ & $32(20 \%)$ & Option II, [31] \\
\hline \multicolumn{7}{|c|}{$\begin{array}{l}\text { - Cerium (50 kt), Lanthanum (30 kT), Neodymium (25 kt, about } 40 \% \text { or } 10 \mathrm{kt} \text { in ICT } \\
\text { and E\&M), Yttrium (11 kt), Other REMs (24 kt) }\end{array}$} \\
\hline Tungsten & 95 & $25 \%$ & $10 \%$ & $80 \%$ & $8(8 \%)$ & Option II \\
\hline Silver & 28 & $30 \%$ & $27 \%$ & $80 \%$ & $4.5(16 \%)$ & Option II \\
\hline Selenium & 4 & & $20 \%$ & $80 \%$ & $0.6(16 \%)$ & Option II \\
\hline Gold & 3.4 & $30 \%$ & $8 \%$ & $80 \%$ & $0.24(6.4 \%)$ & Option II, [32] \\
\hline Tantalum & 1.5 & & $40 \%$ & $80 \%$ & $0.5(32 \%)$ & Option II \\
\hline Indium & 0.8 & & $95 \%$ & $95 \%$ & $0.72(90 \%)$ & Option II \\
\hline Gallium & 0.3 & & $90 \%$ & $90 \%$ & $0.27(81 \%)$ & Option II \\
\hline Platinum & 0.24 & $30 \%$ & $6 \%$ & $80 \%$ & $0.012(5 \%)$ & Option II \\
\hline Palladium & 0.22 & & $15 \%$ & $80 \%$ & $0.026(12 \%)$ & Option II \\
\hline Germanium & 0.12 & $35 \%$ & $89 \%$ & $90 \%$ & $0.1(80 \%)$ & Option II \\
\hline
\end{tabular}




\begin{tabular}{|l|c|l|c|c|c|l|}
\hline Ruthenium & 0.012 & & $80 \%$ & $80 \%$ & $0.009(64 \%)$ & Option II \\
\hline Total: & & & & & $\mathbf{1 4} \mathbf{~ M t}$ & \\
\hline $\begin{array}{l}\text { E\&M paper } \\
\text { consumption }\end{array}$ & 126000 & & & & $126 \mathrm{Mt}$ & $\begin{array}{l}\text { RISI [6], paper } \\
\text { used for media }\end{array}$ \\
\hline \multicolumn{2}{|l|}{ ICT infrastructure materials (steel, concrete, gravel etc.) } & $\sim 20 \mathrm{Mt}$ & $\begin{array}{l}\text { Ericsson estimate } \\
\text { based on [20] }\end{array}$ \\
\hline
\end{tabular}

Table 4: The selected materials and the EEE and ICT and E\&M sectors share

${ }^{1}$ Total production, recycling and the EEE share are based on primarily [7] and other leading market analysts and material industry organizations e.g. [9-13].

${ }^{2}$ Mainly lead-acid batteries ( $70 \%$ of all lead) primarily used by the automotive industry, if batteries are excluded the EEE sector uses about $15 \%$ of all lead.

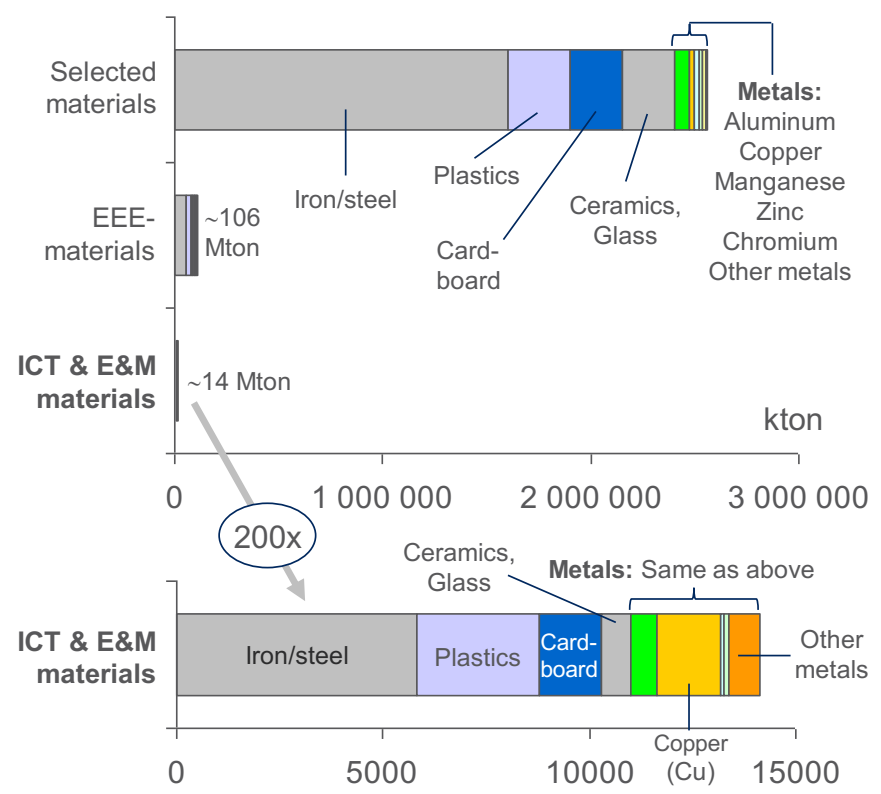

Figure 5: The annual global use of selected materials and the amount used by the EEE sector and the ICT and E\&M sectors. 


\section{B. $\quad$ Material carbon footprint}

Based on the emission factors per kg off weight for the different materials from [28], which are assumed to consider world average recycling, the material carbon footprint of the ICT and E\&M sectors was estimated to about $0.9 \%$ of the selected materials carbon footprint, or $0.1 \%$ of the overall global carbon footprint (including land use), using the material weights from Table III. From a material carbon footprint perspective, the ICT and E\&M sectors thus plays a very minor role despite their use of many rare metals.

Depending on recycling scenario, it is estimated that the ICT and E\&M sectors ranges from $0.6 \%$ to $1.3 \%$ of the selected material carbon footprint, where the lower value corresponds to a EoLT recycling rate of $90 \%$ while the higher value corresponds to no recycling.

\section{Material human and ecosystem toxicity potential}

For the material footprint related to the human and ecosystem toxicity potential, Table $\mathrm{V}$ below shows the materials that are the largest contributors to the human and ecosystem toxicity potential using the ReCiPe based results from [28] for year 2008, extrapolated to the current (2015) total production volumes for each material according to Table IV. The ICT and E\&M shares per materials are set to the shares of weight from Table IV, under the best-effort assumption that these sectors are buying materials from a world market which, for the individual materials, are no better/no worse than the average material produced. This assumption is discussed in section IV.

According to Table V, the total material toxicity footprint for the ICT and E\&M sectors, for the selected materials, is thus estimated to represent about 3.3\% of the overall global material toxicity potential for these materials, or about $10 \mathrm{Pt}$ for one year. It is clear from the share of metals used by the EEE and more specifically the ICT and E\&M sectors in Table IV, and the toxicity potentials in Table V, that copper followed by gold are the key contributors to human and ecosystem toxicity potential. This result is in line with [33].

Testing the results for different recycling rates shows that recycling assumptions are even more important for the human and ecosystem toxicity potential than they are for the carbon footprint. If $100 \%$ recycling could be obtained the toxicity potentials could become nearly zero and only related to the smelters' energy supply source. With no recycling the toxicity potentials could become nearly twice as high.

\begin{tabular}{|c|c|c|c|}
\hline Material toxicity potential $^{1}$ & $\begin{array}{c}\text { Total production } \\
\text { kton }\end{array}$ & $\begin{array}{l}\text { Material toxicity } \\
\text { potential }^{1}(\mathrm{Pt} / \mathrm{yr})\end{array}$ & $\begin{array}{c}\text { ICT+E\&M } \\
\text { material share }(\%)\end{array}$ \\
\hline Copper, $\mathrm{Cu}$ & 25650 & $\sim 105$ & $\sim 6 \%(6 \mathrm{Pt})$ \\
\hline Iron/Steel, Fe & 1600000 & $\sim 100$ & $\sim 0.36 \%$ \\
\hline Gold, Au & 3.4 & $\sim 25$ & $\sim 6.4 \%$ \\
\hline Aluminium, Al & 70000 & $\sim 20$ & $\sim 0.90 \%$ \\
\hline Calcium, $\mathrm{Ca}$ (in cement) & $\sim 4000000$ (cement) & $\sim 10$ & n.a. \\
\hline Molybdenum, Mo & 264 & $\sim 8$ & $\sim 1.3 \%$ \\
\hline Nickel & 2000 & $\sim 6$ & $\sim 1.3 \%$ \\
\hline Zinc, Zn & 14500 & $\sim 6$ & $\sim 0.69 \%$ \\
\hline Silver, Ag & 24 & $\sim 5$ & $\sim 15 \%$ \\
\hline Lead, $\mathrm{Pb}$ & 10000 & $\sim 4$ & $\sim 4.5 \%$ \\
\hline Other materials & $\sim 908000$ & $\sim 20$ & $\sim 2 \%$ \\
\hline
\end{tabular}




\begin{tabular}{l|l|c|}
\hline Total results & $\sim 309$ & $\sim 3.3 \%(10 ~ P t / y r)$ \\
\hline Table 5: Material toxicity potential
\end{tabular}
${ }^{1}$ Using ReCiPe Endpoint method $1.08 \mathrm{H} / \mathrm{H}$ for the globe based on [19] and terminology from [19], human health and
ecosystem damage. Note also that EcoInvent is used as one of the sources by [19] for metal LCA data and EcoInvent tend to
give rare and valuable metals high toxicity potentials due to the long time perspective used when modelling impact.

\section{Material resource depletion footprint (ADP)}

For the material footprint related to ADP the overall global depletion is presented per material in Table $\mathrm{V}$ for three different methods; ultimate reserve (A), reserve base (B) and reserve (C), each of these in accordance with [34]. As for toxicity, the ICT and E\&M shares per materials are set to their shares of weight from Table IV, under the best-effort assumption that these sectors are buying materials from a world market which, for the individual materials, are no better/no worse than the average material produced.

\begin{tabular}{|c|c|c|c|c|}
\hline \multirow{2}{*}{$\begin{array}{l}\text { Material Resource } \\
\text { Depletion potential }\end{array}$} & \multirow{2}{*}{$\begin{array}{c}\text { ICT+E\&M } \\
\text { material share }(\%)\end{array}$} & \multicolumn{3}{|c|}{ Global total ADP (ICT's share of ADP) (\%) } \\
\hline & & A. Ultimate Reserve & B. Reserve base & C. Reserve \\
\hline Gold, Au & 6.4 & $37(2.4)$ & $4(0.3)$ & $4(0.3)$ \\
\hline Antimony, Sb & 25 & $34(8.5)$ & $5(1.3)$ & $5(1.3)$ \\
\hline Silver, Ag & 15 & $6(0.9)$ & $7(1.1)$ & $6(0.9)$ \\
\hline Copper, $\mathrm{Cu}$ & 6 & $5(0.3)$ & $1(0.06)$ & $2(0.1)$ \\
\hline Lead, $\mathbf{P b}$ & 4.5 & $5(0.2)$ & $2(0.09)$ & $3(0.1)$ \\
\hline Sulphur, S & na & 3 & 1 & 2 \\
\hline Boron, B & na & 2 & & \\
\hline Chromium, $\mathrm{Cr}$ & 0.7 & $2(0.01)$ & & \\
\hline Tin, $\mathrm{Sn}$ & 38 & $1(0.4)$ & $1(0.4)$ & $1(0.4)$ \\
\hline Zinc, Zn & 0.7 & $1(0.01)$ & $1(0.01)$ & $3(0.02)$ \\
\hline Germanium, Ge & 80 & & $50(40)$ & $24(19.2)$ \\
\hline Indium, In & 90 & & $5(4.5)$ & $10(9.0)$ \\
\hline Other materials & $N a$ & 4 & 23 & 40 \\
\hline $\begin{array}{l}\text { Total ICT+ E\&M } \\
\text { results }^{1}\end{array}$ & & $13 \%$ & $48 \%$ & $31 \%$ \\
\hline
\end{tabular}

Table 6: Material resource depletion potential

${ }^{1}$. These results are derived by multiplying ICT and E\&M share of weight per material by the corresponding global ADP values (A-C)

The total material resource depletion potential for the selected materials for the ICT and E\&M sectors are calculated by multiplying their weight share of each material by the corresponding global ADP value for each material, for the three methods. Based on this, the footprint is estimated to be about $13 \%$ when applying the ultimate reserve perspective (A) which is the most commonly adopted one in LCAs.

The other two perspectives relates to the present industrial situation, and considers the economic grounds in terms of work and energy inputs for continuing the extraction of resources for which returns are diminishing in a near future. When using these reserve (B) and reserve base (C) perspectives originally defined in [34], the material resource depletion footprint for the ICT and E\&M sectors grows to $48 \%$ and $31 \%$ respectively.

Note that no recycling is included in the derived resource depletion potential, but with world average recycling rates applied with regards to input of materials, the results for the ultimate reserve method (A) decreases from $13 \%$ to $7 \%$. As for the materials carbon and toxicity footprints, recycling rates are important for the resource depletion. If nearly $100 \%$ recycling could be obtained the resource depletion would approach zero. 


\section{Discussion}

\section{A. Some sources of uncertainty}

A study like this that combines a variety of data sets and top-level methodologies are per se associated with high uncertainties that are not easily quantified. Usually broad statistical data sets are lacking which renders a traditional uncertainty assessment of parameter uncertainty difficult. On top of that comes model and scenario uncertainties. Also, data sets from different sources needs to be combined in a way that contain some elements of choice/ judgement. For these reasons it is not considered meaningful to propose an uncertainty range.

A fundamental assumption of this study is that materials used by ICT and E\&M sectors are no better/no worse than the world average materials. Firstly, this is a practical assumption as the long and complex supply chains of ICT and E\&M makes it very hard to track the actual sources of materials. Secondly, as these materials are purchased within a world market there are no indications that ICT and E\&M should represent special conditions in this aspect. Also recycling assumptions are important which has already been dealt with in section II and III.

With regards to data age the ambition has been to model the situation 2015 as closely as possible. In terms of volumes this has been possible, in terms of product and LCA data inputs, yearly data are in most cases not available, but the ambition has rather been to collect as recent and good data as possible. As defined by the scope the focus has been on the annual input of materials so built in stocks of materials have not been considered. Due to the relatively short life time of ICT and E\&M products, the stock perspective is of more limited importance than for sectors with products with longer life spans.

Confidential data has been used for the weight of networks as for network products physical data are often seen as competitive and thus considered as business information. This is of course problematic from a transparency point of view. However, without that approach an important part of the sector would have been left out of the study, which would have meant a considerable data gap.

Double accounting is always a risk when different types of data sources are combined, so efforts have been made to identify and adjust for this as far as possible.

For resource depletion, the different impact assessment methods are all strongly dependent on the (subjective) valuation of specific materials which gives the great variation in results noted between them. For toxicity, results differ largely depending on the method and data set used. This was further described in [16] and is due to differences in time perspectives between LCA data bases. Long time perspectives used for leakages from mining tailings makes a large difference on how ecosystem impacts are estimated.

\section{B. A closer look at gold and copper}

Two metals stand out among the assessed metals due to their higher toxicity and resource depletion potential: gold and copper. These metals are very important for EEE in general, and even more so for the ICT and E\&M sectors. Gold, specifically, provides superior connection properties and allows for smaller and more energy efficient electronic devices. For copper, recycling shares are not increasing as for many other metals as outlined in Section I. One reason may be the increased use of copper in electronics and another reason may be use of copper in cables that are left in the ground or in complex building structures that make recycling difficult and expensive.

Due to the importance and impact of gold and copper for ICT and E\&M, Figure 6 summarizes the overall global material flows and stocks for these metals. A major difference between the two materials is that most gold that has been produced throughout history remains in use or storage, while copper has a considerably shorter lifespan in society. Still $2 / 3$ of the copper mined is believed to remain in use in society [12]. However, from a recycling perspective the use of gold in electronics becomes a problem as the gold is spread in small concentrations and is blended with other materials which makes it challenging to recycle it, so with current recycling methods and shares, valuable gold stocks are loss. 
From a circularity point of view the most important values from Figure 6 are perhaps those referring to new production ( $2.8 \mathrm{kt}$ for gold, and $16 \mathrm{Mt}$ for copper), and an important task of a circular economy would be to move these material streams towards zero. With respect to future availability the known virgin stock is about twice as high as the amount in use for copper and is expected to last some 44 years, while the gold stock is expected to last just below 19 years [32]. For ICT and E\&M that rely on the access to these materials, the implication is that driving forces for moving into a more circular use of materials are related to both the material footprints and the long-term availability.

To decrease the impact from materials, it is important to increase reuse and sharing and other measures to prolong the life time and to decrease the current material demand. However, in the long term the most important issue is to recycle metals and especially rare metals such as gold and copper and recycling rates need to approach $100 \%$ to conserve materials for use by society on longer time scales (millennia).
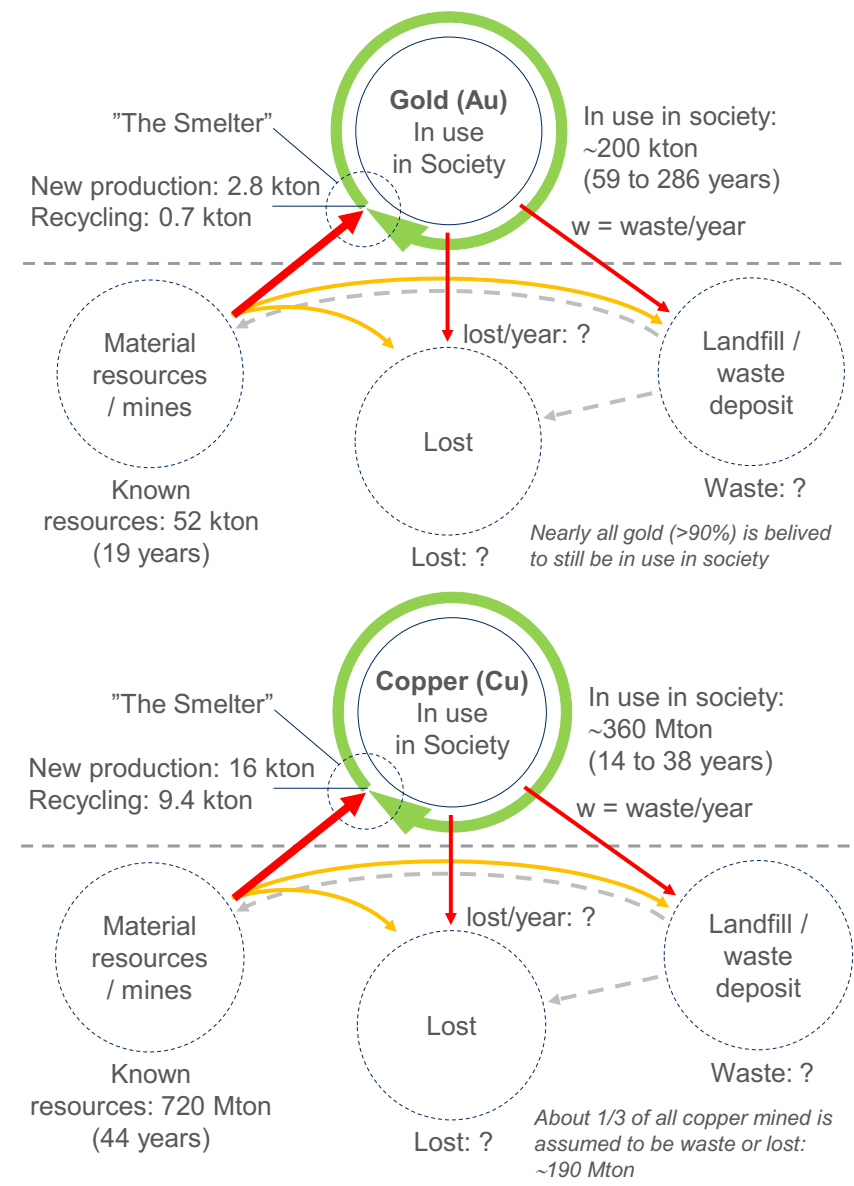

Figure 6a-b: The use of gold (6a) [32] and copper (6b) [12] in society.

\section{C. $\quad$ Future studies}

This study represents a first attempt towards defining the material footprints of the ICT sector and the method applied could give but a rough estimate of the materials footprints. The approach used was mainly top-down, except for the calculation of ICT and E\&M weights which were based on more detailed modelling. A more detailed bottom-up modelling of ICT and E\&M product categories would be a great complement and is suggested to be explored in future studies. 


\section{Conclusions}

Several different types of material footprints were defined and calculated for the ICT and E\&M sector.

The most basic material footprint (by mass or shares of mass) were studied for a large number of selected materials (mainly metals) for which ICT and E\&M sectors represent a significant usage. Electrical and electronic products in general uses about $4 \%$ in weight of these selected materials, and the ICT and E\&M sector about $0.5 \%$. but the share of rare metals is significantly higher, and for several materials (indium, gallium and germanium), ICT and E\&M usage represents as much as $80-90 \%$ of the overall usage.

The material carbon footprint of the ICT and E\&M sectors was found to be about $0.9 \%$ of the selected materials carbon footprint, and about $0.1 \%$ of the total global carbon footprint (including land use) when a global average recycling scenario was used.

The material toxicity footprint for the ICT and E\&M sectors, was estimated to represent about $3.3 \%$ of the impacts related to the global use of the selected materials, plus cement production for input data reasons, and based on the ReCiPe method. The uncertainties for the toxicity potentials are very high and no global overall potential for all materials can be estimated and related to, but the results indicate that the ICT and E\&M sectors play a much larger role than the total materials useage by mass indicates.

Finally, the material footprint defined as the material resource depletion potential, was found to be between $13 \%$ and $48 \%$ of the global material resource depletion potential depending on impact assessment method.

Production yields have not been considered and might add another $10 \%$ to the derived footprints.

Based on the toxicity and resource depletion potential gold and copper are found to be the two of the key metals used by the ICT and E\&M sectors. Other materials of special interest are zinc, lead, and silver (often mined together) from both a toxicity and resource depletion potential perspective, and, from a resource depletion potential perspective antimony, indium, and germanium.

The results represent only a coarse estimate of the actual impacts which may therefore be higher or lower, and complementary bottom-up studies are needed to better understand the impacts of ICT and E\&M. However, as a first attempt towards defining the materials footprint of the sector the study is providing a coarse estimate of the materials and to inspire continued research in the area.

\section{References}

[1] ISO/TS 14067:2013, 2013. Greenhouse gases -- Carbon footprint of products -- Requirements and guidelines for quantification and communication

[2] Wiedmann, T. et al. 2015. The material footprint of nations. PNAS Volume 112, No. 20. ww.pnas.org/cgi/doi/10.1073/pnas.1220362110

[3] Peters, G., Solli, C. 2010. Global carbon footprints. Nordic Council of Ministers 2010. ISBN 978-92-893-2159-4

[4] Willi Haas, Fridolin Krausmann, Dominik Wiedenhofer, and Markus Hein. How Circular is the Global Economy? An Assessment of Material Flows, Waste Production, and Recycling in the European Union and the World in 2005. Journal of Industrial Ecology. Volume 19, No. 5. DOI: 10.1111/jiec.122

[5] Ellen McArthur Foundation, 2013. Towards the Circular Economy Vol. 1: an economic and business rationale for an accelerated transitionPulp and Paper Industry Intelligence (RISI)

[6] RISI. 2015. Pulp and Paper Industry Intelligence. Outlook for the world paper grade pulp market.

[7] International Organizing Committee for the World Mining Congresses. 2017. World Mining Data 2017. Federal Ministry of Science, Research and Economy. Vienna. www.bmwfw.gv.at

[8] Geyer, R., Jambeck, J. R., Law, K. L. 2017. Production, use, and fate of all plastics ever made. Published 19 July 2017 , Sci. Adv. 3, e1700782 (2017) DOI: 10.1126/sciadv.1700782 
[9] Bureau of International Recycling, Ferrous Division. 2013. World Steel Recycling in Figures 2008 - 2012.

[10] Mudd, Gavin M. 2010. The Arrival of Peak Lead: Peak Environmental Impacts? LEAD Action News vol 11 no 1, September 2010 ISSN 1324-6011

[11] International Aluminium Institute. 2009. Global Aluminium Recycling: A Cornerstone of Sustainable Development.

[12] International Copper Association. Copper Recycling. 2014.

[13] Glöser, Simon; Soulier, Marcel; Tercero Espinoza, Luis A. (2013): A dynamic analysis of global copper flows. Global stocks, postconsumer material flows, recycling indicators \& uncertainty evaluation. In Environ. Sci. Technol. (in press) DOI: 10.1021/es400069b. http://pubs.acs.org/doi/abs/10.1021/es400069b

[14] Wäger, P.A., Hischier, R., Widmer, R., 2015, The material basis of ICT, ICT innovations for Sustainability, Advances in Intelligent Systems and computing 310, DOI 10.1007/978-3-319-09228-7_12

[15] Vienna University of Economics and Business. 2015. http://www.materialflows.net/materialflowsnet/trends/analyses1980-2013/material-intensity-by-world-region-1980-2013/

[16] ETSI/ITU] ca 15 ITU-T L.1410 (12/14), 2014. Methodology for environmental life cycle assessments of information and communication technology goods, networks and services

[17] Malmodin, J. el al. (2015), Exploring the effect of ICT solutions on GHG emissions in 2030. Paper published and presented at: ICT for Sustainability (ICT4S), Copenhagen, Denmark, 7-9 September 2015.

[18] Baldé, C.P., Wang, F., Kuehr, R., Huisman, J. (2015), The global e-waste monitor - 2014, United Nations University, IAS - SCYCLE, Bonn, Germany.

[19] Baldé, C.P., Forti V., Gray, V., Kuehr, R., Stegmann,P. : The Global E-waste Monitor - 2017, United Nations University (UNU), International Telecommunication Union (ITU) \& International Solid Waste Association (ISWA), Bonn/Geneva/Vienna.

[20] IC Insights. 2017. IC Market Drivers. http://www.icinsights.com/services/ic-market-drivers/

[21] IPC. 2017. Printed Circuit Board (PCB) Industry Reports and Electronics Manufacturing Services (EMS) and Assembly Reports. http://www.ipc.org/3.0 Industry/3.2 Market_Research/Market-Research-Reports-Brochure.pdf

[22] Louisa Winnik. Integer Research. 2015. Structural change and the competitive challenge in the global wire \& cable business. $28^{\text {th }}$ International Copper Conference. 25-27 Feb 2015 Brussels, Belgium. http://www.metalbulletin.com/events/presentations/7570/28th-international-copperconference/a0ID000000X0kAOMAZ/016-louisa-winnikpdf.html

[23] IHS. Global major home appliances market forecast for shipments and revenue. https://technology.ihs.com/Services/503435/home-appliance-intelligence-service

[24] ABB. Infographic - Powering the World's Economy. http://www04.abb.com/global/seitp/seitp202.nsf/0/ec96823a06519347c12578b500362974/\$file/ABB ElectricMotors inf ographic.pdf

[25] Mitsubishi. Specification for PV-MLU250HC $250 \mathrm{~W}$ PV Module. www.mitsubishielectricsolar.com

[26] FMI (Future Market Insights). Power Tools Market. 2015-2025. https://www.futuremarketinsights.com/reports/power-tools-market

[27] Malmodin, J. et al. 2014. Life cycle assessment of ICT - Carbon footprint and operational electricity use from the operator, national and subscriber perspective in Sweden. Journal of Industrial Ecology, 18 (6), 829-845.

[28] Nuss P, Eckelman MJ (2014) Life Cycle Assessment of Metals: A Scientific Synthesis. PLoS ONE 9(7): e101298. doi:10.1371/journal.pone.0101298

[29] Nickel Institute. Sustainability of Stainless Steels. https://nickelinstitute.org/ /media/Files/KnowledgeBase/TrainingModules/StainlessSteelforLectures/Module 11 Sustain ability.ashx?la=en

[30] Dupont, D. et al. 2016. Antimony Recovery from End-of-Life Products and Industrial Process Residues: A Critical Review. Journal of Sustainable Metallurgy. DOI 10.1007/s40831-016-0043-y

[31] AMR Mineral. REE Industry Facts. http://amrmineral.com/download/corporate/REE Industry.pdf

[32] Boston Consulting Group. 2015. The ups and down of gold recycling. Understanding Market Drivers and Industry Challenges. On behalf of World Gold Council.

[33] Ercan, M. et al. (2016). Life cycle assessment of a smartphone. Paper published and presented at: ICT for Sustainability (ICT4S), Amsterdam, Netherlands, 30-31 August 2016.

[34] Huppes, G. 2002. Abiotic resource depletion in LCA. Institute of Environmental Sciences (CML). https://www.leidenuniv.nl/cml/ssp/projects/lca2/report_abiotic_depletion_web.pdf 